\title{
Current management practice for bladder cancer in Hong Kong: a hospital-based cross-sectional survey
}

\author{
Eddie SY Chan *, CH Yee, SM Hou, CF Ng
}

This article was published on 28 Mar 2014 at www.hkmj.org.

\section{A B S T R A C T}

Objectives: To examine current practice in the management of bladder cancer in Hong Kong government and private hospitals.

Design: Cross-sectional survey.

Setting: All government hospitals and the major private institutions in Hong Kong, which provide urological services.

Participants: Urologists responding to an anonymous, self-administered, web-based questionnaire regarding practices in smoking cessation, treatment of non-muscle invasive bladder cancer and muscle invasive bladder cancer, and research into bladder cancer.

Results: Of the 29 urologists from 11 government hospitals and eight private institutions who were invited, 18 from 11 (100\%) government hospitals and seven from six (75\%) private institutions responded, which amounted to an $86 \%$ response rate. In all, $88 \%$ of the respondents seldom or never referred their bladder cancer patients to smoking cessation programmes. Hong Kong urologists showed good compliance in the management of non-muscle invasive bladder cancer according to international guidelines. There was great variation with regard to regimens for maintenance of intravesical immunotherapy. There was underuse of perioperative systemic chemotherapy, despite wide acceptance of this practice; fewer than $10 \%$ of the patients received neo-adjuvant and adjuvant systemic chemotherapy for the treatment of muscle invasive bladder cancer. Of the surveyed urologists, $80 \%$ expressed an inadequacy of resources for bladder cancer research and $96 \%$ agreed that a local inter-hospital bladder cancer database was needed.

Conclusions: This study demonstrated great diversity in the use of intravesical immunotherapy, perioperative systemic chemotherapy, and surgical treatment of bladder cancer among urology service providers. There is a need for clear recommendations in these areas.

\section{Hong Kong Med J 2014;20:229-33 DOI: $10.12809 / \mathrm{hkmj} 134064$}

ESY Chan *, MD, FHKAM (Surgery)

CH Yee, FRCS (Edin), FHKAM (Surgery)

SM Hou, FRCS (Edin), FHKAM (Surgery)

CF Ng, MD, FHKAM (Surgery)

Division of Urology, Department of Surgery, Prince of Wales Hospital, The Chinese University of Hong Kong, Shatin, Hong Kong

* Corresponding author: eddie@surgery.cuhk.edu.hk

\section{New knowledge added by this study \\ - By providing important information on practice preferences in the management of bladder cancer in both the public and private sectors in Hong Kong, this study demonstrates the great diversity in the use of intravesical immunotherapy, perioperative systemic chemotherapy, and surgical treatments. \\ Implications for clinical practice or policy \\ Local guidelines in bladder cancer management and the use of intravesical bacillus Calmette-Guérin are needed.}

\section{Introduction}

Bladder cancer is a common genitourinary malignancy. It is the fifth most frequent cancer in the US, where it accounts for $7 \%$ of all incident malignancies. ${ }^{1}$ In 2009, there were 372 newly diagnosed bladder cancer cases in Hong Kong. ${ }^{2}$ Patients with bladder cancer warrant close surveillance because of high recurrence and progression rates (50-70\%). ${ }^{3}$ Due to its prolonged natural history, intensive follow-up and treatment strategies, management of this cancer is costly and is the most expensive malignancy to treat on a perpatient basis., ${ }^{4,5}$

Guidelines for bladder cancer management have been established in an attempt to improve treatment outcomes. The most commonly used are the American Urological Association (AUA), European Association of Urology (EAU), and National Comprehensive Cancer Network (NCCN) guidelines. There is no specific guideline in Hong Kong. The practice in bladder cancer treatment in Hong Kong may differ among urologists 


\section{香港治療膀胱癌的現行做法：以醫院為基礎的 橫斷面調查 \\ 陳樹賢、余知行、侯仕明、吳志煇 \\ 目的：探討現行香港政府和私營醫院對膀胱癌治療的做法。 \\ 設計：㮨斷面研究。 \\ 安排：所有提供泌尿科服務的香港政府和私營醫院。}

參與者: 受訪的泌尿科醫生會自行填寫一份匿名的網上問卷, 訪問他 們有關對膀胱癌患者的處理, 包括戒煙、非肌層浸潤和肌層浸潤性膀 胱癌的治療, 及有關膀胱癌的研究。

結果：本研究的對象為代表 11 間政府醫院和 8 間私人機構的 29 位泌尿 科醫生。當中收到來自 11 間（100\%）政府醫院中18名和6間（75\%） 私營醫院中7名泌尿科醫生的回應; 總回答率為 $86 \%$ 。研究發現, $88 \%$ 的受訪醫生很少或從來沒有轉介膀胱癌病人參與戒煙計劃。在非肌層 浸潤膀胱癌治療上, 香港泌尿科醫生均遵守國際準則。根據觀察所 得, 各泌尿科中心在預防癌患治理維持方案的膀胱內免疫治療存在很 多差異。儘管圍手術期全身化療的好處被廣泛接受, 可是它的使用率 不足; 只有不足 $10 \%$ 的肌層浸潤性膀胱癌患者接受新輔助和輔助全身 化療治療。 $80 \%$ 的受訪泌尿科醫生表示膀胱癌研究的資源不足, $96 \%$ 則認同需要一個本地醫院間互通的膀胱癌數據庫。

結論：這項研究表明了在泌尿科服務提供者之間使用膀胱內免疫治 療、圍手術期全身化療和手術治療膀胱癌等均存在巨大差異。有必要 在這些方面設立明確的指引。 and centres. The aim of this survey was to gain better understanding of current bladder cancer management practice in Hong Kong.

\section{Methods}

\section{Questionnaire and data collection}

An online multiple-choice questionnaire was sent to all government hospitals and major private institutions providing urological services. Senior urologists from corresponding hospitals were invited to respond to the questionnaire, which was anonymous, self-administrated, and non-validated. From each centre at least one urologist was encouraged to respond. If the hospital or centre had three or more board-certified urologists, no more than two were encouraged to complete the survey, so as to be as representative as possible. The responses from the surveyed urologists were submitted and collected over a secured connection.

The questionnaire comprised 30 questions divided into three sections: (1) General Issues and Smoking Cessation, (2) Management and Treatment, and (3) Bladder Cancer Research. The first part concerned the daily workload for bladder cancer and smoking cessation programmes. The second part (the main part of the survey) evaluated management preferences for non-muscle invasive bladder cancers (NMIBCs) and muscle invasive bladder cancers (MIBCs), and included questions regarding intravesical and systemic chemotherapy. The final part addressed the adequacy of resources and progress for bladder cancer research.

\section{Statistical analysis}

Data were presented as descriptive statistics of the main variables and analysed using Excel (Version 14.2, California, US). A frequency table was constructed to indicate the management preferences.

\section{Results}

Between March and August 2012, 19 hospitals and institutions from both government $(n=11)$ and private $(n=8)$ sectors were involved in this study. Twenty-nine senior urologists from corresponding hospitals were invited to participate in the survey. Responses from 11 (100\%) government hospitals and six $(75 \%)$ private sector institutions were received. Of the 29 invited urologists, 18 were from public hospitals and 11 from private institutions; eventually, $25(86 \%)$ responded to the survey and completed the questionnaires (18 [100\%] from public hospitals and 7 [64\%] from the private sector).

\section{Part 1: general issues and smoking cessation}

Among the surveyed urologists, 17 (68\%) estimated that $10 \%$ to $25 \%$ of their clinical workload was spent on diagnosis, treatment, and surveillance of bladder cancer. Whilst cigarette smoking is a key risk factor for bladder cancer, 14 (56\%) commented that there was no access to a smoking cessation programme in their hospitals. Notably, $22(88 \%)$ seldom or never referred their patients to any smoking cessation programme. Only $11(44 \%)$ and $10(40 \%)$ of the respondents thought that resources for smoking cessation were readily or easily available to patients and urologists, respectively.

\section{Part 2: management and treatment}

Guidelines from AUA and EAU remain the most useful guides for bladder cancer management. None of the surveyed urologists used the guideline published by the Chinese Urological Association. However, 12 (48\%) of the respondents had a bladder cancer management guideline in their own hospital and $15(60 \%)$ expressed the need for a local Hong Kong guideline.

Among the surveyed hospitals, immediate intravesical chemotherapy was always $(56 \%)$ or often (44\%) administered. All hospitals (100\%) used mitomycin $\mathrm{C}$ as the chemotherapeutic drug of choice. Currently, international guidelines also advocate a second transurethral resection of the bladder tumour (TURBT) for patients with highrisk NMIBC or in the absence of detrusor muscle in 
bladder tissue specimens. While all the respondents from government hospitals adopted this concept, five $(28 \%)$ of them "always", and $13(72 \%)$ of them "often" performed a second TURBT. On the contrary, four $(57 \%)$ of the urologists in private institutions seldom practised a second procedure. Overall, the common problems of a second TURBT encountered by urologists included a tight operation schedule (48\%) and refusal by patients (16\%).

All the surveyed hospitals always (44\%) or often (56\%) prescribed intravesical bacillus CalmetteGuérin (BCG) for high-risk NMIBC patients. However, there was a great variation in the duration of intravesical immunotherapy regimens in the 17 hospitals with responding urologists. The Table shows that the durations ranged from induction with no maintenance (24\%), to maintenance for 3 months (6\%), 1 year (35\%), 1.5 years (6\%), 2 years (6\%), and 3 years (24\%). Of the 25 surveyed urologists, $76 \%(n=19)$ encountered problems in intravesical immunotherapy, which were related to the poor patient compliance stemming from side-effects (60\%) and serious BCG-related complications (16\%).

Open radical cystectomy remains the most common approach in Hong Kong. Of the 17 surveyed hospitals whose urologists responded, only three (18\%) government hospitals routinely practised radical cystectomy with a minimally invasive approach. Most of the surveyed urologists thought that systemic chemotherapy was useful in selected MIBC patients in neo-adjuvant (56\%) and adjuvant (76\%) settings. However, all but one hospital reported that less than $10 \%$ of their patients received either neo-adjuvant or adjuvant chemotherapy. The low frequency of systemic perioperative chemotherapy could be due to patient refusal or poor tolerance of systemic chemotherapy. Oncologists' refusal to provide chemotherapy in neo-adjuvant $(28 \%)$ and adjuvant (36\%) settings could also be the reason (Fig).

\section{Part 3: bladder cancer research}

Among the respondents, 13 (52\%) thought that current management regimens were adequate for diagnosing and preventing bladder cancer recurrence/progression, whilst 12 (48\%) felt that progress on bladder cancer treatment research was poor compared to that for renal cell and prostate cancer. Most of the respondents (80\%) stated that resources for bladder cancer research were inadequate, and most (96\%) also expressed a need for an inter-hospital bladder cancer database to improve patient care.

\section{Discussion}

Bladder cancer is among the commonest urological malignancies. Patients with bladder cancer demand close surveillance for recurrence and progression.
TABLE. Duration of intravesical immunotherapy in different hospitals

\begin{tabular}{lccc}
\hline Intravesical immunotherapy & Private $(\mathbf{n = 6 )}$ & Public $(\mathbf{n = 1 1 )}$ & No. (\%) \\
\hline Induction only & 3 & 1 & $4(24)$ \\
Induction + 3-month maintenance & 1 & 0 & $1(6)$ \\
Induction + 1-year maintenance & 1 & 5 & $6(35)$ \\
Induction + 1.5-year maintenance & 0 & 1 & $1(6)$ \\
Induction + 2-year maintenance & 0 & 1 & $1(6)$ \\
Induction + 3-year maintenance & 1 & 3 & $4(24)$ \\
\hline
\end{tabular}

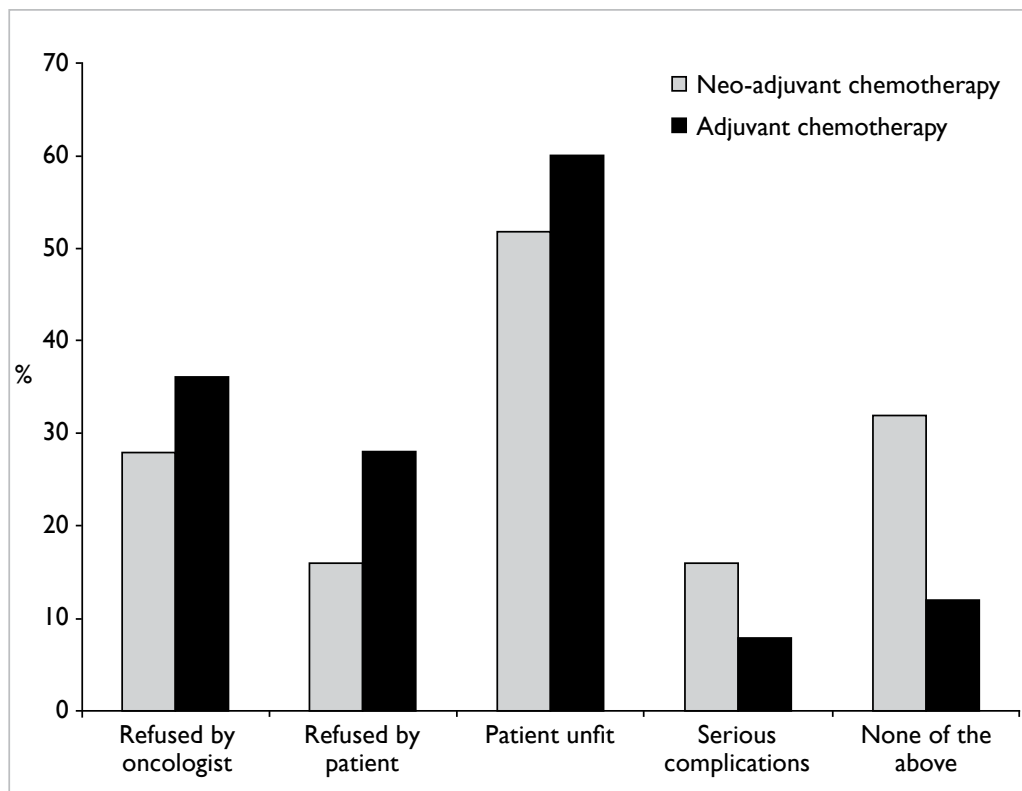

FIG. Common problems encountered by urologists about neo-adjuvant and adjuvant chemotherapy

Thus, one fourth of the workload of urologists is spent on the diagnosis, treatment, and surveillance of bladder cancer patients. Because of the complicated treatment and follow-up strategies, it is also the most costly to treat, ${ }^{4,5}$ and there is a wide variation in the practice patterns and compliance to guidelines. ${ }^{6}$ In Hong Kong, bladder cancer incidence is on a decreasing trend in both sexes, but the crude mortality rate has not changed in the last decade. ${ }^{2}$ There are no data available regarding the preferred management patterns of Hong Kong urologists on bladder cancer. Herein, we report on the first crosssectional survey of clinical practice for a specific urological disease category in Hong Kong. Such information can be important for urologists, health policy-makers, and patients.

Smoking is the most important preventable cause of death in Hong Kong and many countries. Diseases caused by smoking impose a heavy 
economic and medical burden on our society. Many countries therefore have enhanced efforts to promote smoking cessation in addition to strengthening tobacco control measures and legislation. Cigarette smoking is a well-established risk factor for bladder cancer, and accounts for up to $50 \%$ of all incident bladder cancers. ${ }^{7}$ The risk of bladder cancer in smokers is 2 to 5 times higher than that in non-smokers. Smoking cessation decreases the bladder cancer risk as well as the recurrence rate of such tumours. ${ }^{8}$ Continuing to smoke is associated with worse cancer-related outcomes than in those who quit. In this context, urologists play a vital role in influencing patient knowledge about smoking risks and encouraging cessation of the habit. Guzzo et $\mathrm{al}^{9}$ reported that $76 \%$ of bladder cancer patients in tertiary referral centres received no specific intervention to aid smoking cessation. A number of trials confirmed that interventions from trained health care professionals increase success rates in smoking cessation attempts. ${ }^{10}$ At present, there are a number of local smoking cessation clinics run by the Department of Health (Tung Wah Group of Hospitals, the Pok Oi Hospital, the Hospital Authority, and other organisations). These programmes cover a comprehensive range of activities that include smoking cessation services, education for the public, and research. In our study, $88 \%$ of the respondents seldom or never referred their patients to any smoking cessation programme, and nearly $60 \%$ claimed that smoking cessation facilities were difficult for patients and doctors to access. This is a disappointing statistic that needs to be addressed.

International guidelines set forth by the AUA, EAU, and NCCN are widely adopted by Hong Kong urologists. There is good consensus on the practice of second TURBT and perioperative intravesical chemotherapy between different guidelines for NMIBC patients. $^{11}$ Evidence supports the use of single-dose, immediate postoperative intravesical instillation of mitomycin $C$ to decrease tumour recurrence. Second TURBT within 6 weeks of initial resection enables better tissue sampling and reduces early tumour recurrence. A US study of 14677 bladder cancer patients between 1997 and 2004 found that only $49(0.33 \%)$ received immediate intravesical chemotherapy after TURBT. ${ }^{12}$ Cookson et $\mathrm{al}^{13}$ reported that $66 \%$ of the US-based urologists never used postoperative intravesical chemotherapy. Gontero et $\mathrm{al}^{14}$ evaluated the adherence to EAU guidelines in eight Italian referral centres and found that only $49 \%$ of high-risk patients underwent a repeat TURBT. A study based on SEER-Medicare data reported that only $7.7 \%$ of patients with high-grade NMIBC underwent a second TURBT. ${ }^{15}$ Hong Kong urologists appear to have excellent compliance with both intravesical chemotherapy and performance of a second TURBT in the management of NMIBC patients. Urologists in the private sector seem to achieve a lower rate of second TURBT, which may be due to patient preference, expectations, and financial concerns.

Intravesical instillation of BCG is a standard therapy after TURBT for intermediate or high-risk NMIBC, as there is evidence that bladder tumour recurrence or progression is prevented by such therapy. ${ }^{3}$ For optimal efficacy, an induction course followed by maintenance therapy is recommended, but the duration of maintenance therapy remains controversial. Böhle et $\mathrm{al}^{16}$ suggested that at least 1 year of maintenance BCG was required to prevent recurrence or progression. However, a meta-analysis of 20 trials was unable to determine which BCG maintenance schedule was the most effective. ${ }^{17}$ Recently, the benefit of maintenance BCG has been challenged. ${ }^{18}$ This practice is further complicated by significant toxicity and a high treatment cessation rate. Given the uncertainty surrounding the optimal intravesical immunotherapy, urologists in Hong Kong vary in how they deliver such treatment. Having a consensus on optimal intravesical BCG therapy is challenging but necessary, before further research involving randomised clinical trials is undertaken.

Minimally invasive (laparoscopic/robotic) surgical approaches have been widely used by local urologists, including for nephrectomy and prostatectomy. These help reduce morbidity, shorten hospital stays, and enhance recovery. Open radical cystectomy remains the standard treatment for MIBC patients. Laparoscopic or robot-assisted radical cystectomy is among the most challenging procedures and performed in a limited number of centres where the necessary experience and expertise exists. ${ }^{19}$ The situation in Hong Kong is similar, while open radical cystectomy is the most preferred approach.

The pattern of treatment for MIBC has changed to a multidisciplinary approach. There is growing evidence that perioperative chemotherapy provides survival benefits in such patients. Meta-analysis suggests that neo-adjuvant and probably adjuvant systemic chemotherapy too increase cancer-specific and overall survivals. ${ }^{20,21}$ Porter et $\mathrm{al}^{22}$ reported that only $2.6 \%$ of stage 2 and $12.7 \%$ of stage 4 patients with bladder cancer received either neo-adjuvant or adjuvant chemotherapy. The underutilisation of perioperative systemic therapy was also observed in our survey. Non-tumour-related factors (including patient age, co-morbidity, and oncologists' preferences) influence treatment patterns. Such practice is not consistent with current evidence and recommendations, all of which may affect outcomes of bladder cancer patients.

While substantial progress has ensued in the 
field of other genitourinary malignancies, bladder cancer research lags behind. Under-enrolment, lack of specific funding for bladder cancer, and lack of cooperative group trials are some of the problems that research needs to overcome. An inter-hospital cancer database could provide important information to clinicians and health care administrators so as to formulate health care plans. Relevant outcome data could benefit both urologists and patients, when it comes to improving bladder cancer treatment. ${ }^{23}$

There are several limitations to be noted regarding this study. First, the survey was a retrospective review of practice. Second, the reported numbers and percentages were estimations without any verification, which may have introduced inaccuracy and recall bias. Third, this was a hospitalbased survey instead of being individual-based, with 11 government and eight private hospitals that provide urology services. It nevertheless covered common local practice in most of the hospitals and institutions, and should be representative. Fourth, currently there are about 100 board-certified practising urologists in Hong Kong, so surveying a larger number of urologists might have yielded a broader view of practice patterns at an individual level.

\section{Conclusions}

This study provided important information on practice preferences in the management of bladder cancerin both publichospitals and private institutions in Hong Kong. It demonstrated great diversity in the use of intravesical immunotherapy, perioperative systemic chemotherapy, and surgical treatment of bladder cancer in different urology centres. There is a need for clear local recommendations and guidelines in these areas.

\section{References}

1. Jemal A, Siegel R, Xu J, Ward E. Cancer statistics, 2010. CA Cancer J Clin 2010;60:277-300.

2. Hong Kong Cancer Registry, Hospital Authority. Available from: http://www3.ha.org.hk/cancereg/. Accessed 4 Nov 2012.

3. Lamm DL, Blumenstein BA, Crissman JD, et al. Maintenance bacillus Calmette-Guerin immunotherapy for recurrent TA, T1 and carcinoma in situ transitional cell carcinoma of the bladder: a randomized Southwest Oncology Group Study. J Urol 2000;163:1124-9.

4. Botteman MF, Pashos CL, Redaelli A, Laskin B, Hauser R. The health economics of bladder cancer: a comprehensive review of the published literature. Pharmacoeconomics 2003;21:1315-30.

5. Avritscher EB, Cooksley CD, Grossman HB, et al. Clinical model of lifetime cost of treating bladder cancer and associated complications. Urology 2006;68:549-53.

6. Chamie K, Saigal CS, Lai J, et al. Compliance with guidelines for patients with bladder cancer. Cancer 2011;117:5392401.

7. Zeegers MP, Tan FE, Dorant E, van Den Brandt PA. The impact of characteristics of cigarette smoking on urinary tract cancer risk: a meta-analysis of epidemiologic studies. Cancer 2000;89:630-9.

8. Fleshner N, Garland J, Moadel A, et al. Influence of smoking status on the disease-related outcomes of patients with tobacco-associated superficial transitional cell carcinoma of the bladder. Cancer 1999;86:2337-45.

9. Guzzo TJ, Hockenberry MS, Mucksavage P, Bivalacqua TJ, Schoenberg MP. Smoking knowledge assessment and cessation trends in patients with bladder cancer presenting to a tertiary referral center. Urology 2012;79:166-71.

10. Carson KV, Verbiest ME, Crone MR, et al. Training health professionals in smoking cessation. Cochrane Database Syst Rev 2012;(5):CD000214.

11. Brausi M, Witjes JA, Lamm D, et al. A review of current guidelines and best practice recommendations for the management of nonmuscle invasive bladder cancer by the International Bladder Cancer Group. J Urol 2011;186:215867.

12. Madeb R, Golijanin D, Noyes K, et al. Treatment of nonmuscle invading bladder cancer: do physicians in the United States practice evidence based medicine? The use and economic implications of intravesical chemotherapy after transurethral resection of bladder tumors. Cancer 2009;115:2660-70.

13. Cookson MS, Chang SS, Oefelein MG, Gallagher JR, Schwartz B, Heap K. National practice patterns for immediate postoperative instillation of chemotherapy in nonmuscle invasive bladder cancer. J Urol 2012;187:1571-6.

14. Gontero P, Oderda M, Altieri V, et al. Are referral centers for non-muscle-invasive bladder cancer compliant to EAU guidelines? A report from the vesical antiblastic therapy Italian study. Urol Int 2011;86:19-24.

15. Skolarus TA, Ye Z, Montgomery JS, et al. Use of restaging bladder tumor resection for bladder cancer among medicare beneficiaries. Urology 2011;78:1345-9.

16. Böhle A, Jocham D, Bock PR. Intravesical bacillus Calmette-Guerin versus mitomycin $C$ for superficial bladder cancer: a formal meta-analysis of comparative studies on recurrence and toxicity. J Urol 2003;169:90-5.

17. Sylvester RJ, van der Meijden AP, Lamm DL. Intravesical bacillus Calmette-Guerin reduces the risk of progression in patients with superficial bladder cancer: a meta-analysis of the published results of randomized clinical trials. J Urol 2002;168:1964-70.

18. Herr HW. Is maintenance bacillus Calmette-Guérin really necessary? Eur Urol 2008;54:971-3.

19. Imkamp F, Herrmann TR, Rassweiler J, et al. Laparoscopy in German urology: changing acceptance among urologists. Eur Urol 2009;56:1074-81.

20. Stadler WM, Lerner SP. Perioperative chemotherapy in locally advanced bladder cancer. Lancet 2003;361:1922-3.

21. Advanced Bladder Cancer (ABC) Meta-analysis Collaboration. Neoadjuvant chemotherapy in invasive bladder cancer: update of a systematic review and metaanalysis of individual patient data advanced bladder cancer (ABC) meta-analysis collaboration. Eur Urol 2005;48:202-5.

22. Porter MP, Kerrigan MC, Donato BM, Ramsey SD. Patterns of use of systemic chemotherapy for Medicare beneficiaries with urothelial bladder cancer. Urology 2011;29:252-8.

23. Chan ES, Chu SK, Lam KM, Ng CF. Radical cystectomy for the treatment of bladder cancer: What have we learnt from Surgical Outcomes Monitoring and Improvement Program reports? Surg Pract 2012;16:164-7. 